\title{
ĐIỀU TRA THÀNH PHẦn TUYẾN TRÙNG HẠI KHOAI TÂY (Solanum tuberosum) TẠI ĐÀ LẠT
}

\author{
Lê Thị Ngọca $c^{\mathrm{a}}$ Trần Trung Kiêna ${ }^{\mathrm{a}}$, Nguyễn Ngọc Kiều Oanh ${ }^{\mathrm{a}}$, \\ Hoàng Thị Thu Thảo ${ }^{\mathrm{a}}$, Lê Bá Lếa ${ }^{\mathrm{a}}$ Hồ Thị Thu Hòa ${ }^{\mathrm{a}}$, Trần Thị Minh Loan ${ }^{\mathrm{a}^{*}}$ \\ ${ }^{a}$ Khoa Nông Lâm, Truòng Đại học Đà Lạt, Lâm Đồng, Việt Nam \\ "Tác giả liên hệ: Email: loanttm@dlu.edu.vn
}

Lịch sử bài báo

Nhận ngày 15 tháng 06 năm 2017 | Chỉnh sửa ngày 09 tháng 11 năm 2017

Chấp nhận đăng ngày 15 tháng 11 năm 2017

\section{Tóm tắt}

Điều tra xác định thành phần tuyến trùng ký sinh thực vật bằng mô tả hình thái tuyến trùng tuổi hai và tuyến trùng truởng thành. Xác định mật số tuyến trùng trong đất và trong rễ khoai tây bằng phuơng pháp Baermann cải biên, mức độ gây hại của tuyến trùng bằng phuơng pháp của Bridge và Page (1980). Qua quá trình điều tra đã xác định được sáu giống thuộc năm ho và một bộ tuyến trùng thực vật ký sinh gây hại trên khoai tây. Trong đó giống Helicotylenchus có tần suất xuất hiện cao nhất với $93.33 \%$, Meloidogyne có tần suất xuất hiện $83.33 \%$, Pratylenchus có tần suất xuất hiện $50 \%$, và Criconemella có tần suất xuất hiện $33.33 \%$, Ditylenchus có tần suất xuất hiện 30\%, Globodera có tần suất xuất hiện $20 \%$ trong tông số 30 vươn được điều tra. Mật số tuyến trùng ký sinh gây hại trong đất phổ biến ở khoảng tù 500 cá thể đến 3,000 cá thể trong $50 \mathrm{~cm}^{3}$ đất, trong rễ tù 200 đên 2,204 cá thể và mức độ gây hại là 1,754 đến mức 5,262.

Từ khóa: Globodera; Helicotylenchus; Khoai tây; Meloidogyne; Pratylenchus; Tuyến trùng ký sinh thực vật.

DOI: http://dx.doi.org/10.37569/DalatUniversity.9.2.584(2019)

Loại bài báo: Bài báo nghiên cứu gốc có bình duyệt

Bản quyền @ 2019 (Các) Tác giả.

Cấp phép: Bài báo này được cấp phép theo CC BY-NC-ND 4.0 


\title{
SURVEY OF PLANT PARASITIC NEMATODES ON POTATOES IN DALAT
}

\author{
Le Thi Ngoca, Tran Trung Kiena, Nguyen Ngoc Kieu Oanha \\ Hoang Thi Thu Thao ${ }^{a}$, Le Ba Le ${ }^{\mathrm{a}}$, Ho Thi Thu Hoa ${ }^{a}$, Tran Thi Minh Loan ${ }^{a^{*}}$ \\ ${ }^{a}$ The Faculty of Agriculture Forestry, Dalat University, Lamdong, Vietnam \\ ${ }^{*}$ Corresponding author: Email: loanttm@dlu.edu.vn
}

\author{
Article history \\ Received: June $15^{\text {th }}, 2017 \mid$ Received in revised form: November $9^{\text {th }}, 2017$ \\ Accepted: November $15^{\text {th }}, 2017$
}

\begin{abstract}
Plant-parasitic nematodes on potato were identified by morphology of juveniles and adults. Extraction of vermiform nematodes in soil and roots was made by modified Baermann technique and root gall index was dertermined following Bridge and Page (1980) chart. Results show that there were six genus, five families and one order of parasitic-plant nematodes in soil. The ratio of Helicotylenchus was the highest (93.33\%), followed by Meloidogyne (83.33\%), Pratylenchus (50\%), Criconemella (33.33\%), Ditylenchus (30\%), and Globodera at only 20\%. Density of plant parasitic nematodes ranged from 500 individuals to 3,000 individuals per $50 \mathrm{~cm}^{3}$ of soil, 200 to 2,204 individuals per 5 grams of roots. Root gall index ranged from 1,754 to 5,262.
\end{abstract}

Keywords: Globodera; Helicotylenchus; Meloidogyne; Plant parasitic nematodes; Potato; Pratylenchus.

DOI: http://dx.doi.org/10.37569/DalatUniversity.9.2.584(2019)

Article type: (peer-reviewed) Full-length research article

Copyright (C) 2019 The author(s).

Licensing: This article is licensed under a CC BY-NC-ND 4.0 


\section{MỞ ĐẦU}

Khoai tây là cây lương thực có nhu cầu và mức tiêu thụ cao trên thế giới, được xếp hạng thứ tư sau lúa nước, lúa mì, và ngô (Minor \& Bond, 2016). Theo số liệu của Tổ chức Nông lương Liên hiệp quốc năm 2014, diện tích khoai tây trên thế giới là 19,098,328 ha với tổng sản lượng 381 triệu tấn (FAOSTAT, 2017). Năm 2014, Việt Nam có tổng diện tích trồng khoai tây khoảng 22,823 ha. Tuy nhiên diện tích trồng khoai tây tập trung chủ yếu ở một số tỉnh thành phía bắc và Lâm Đồng. Tại Lâm Đồng, diện tích trồng khoai tây vào khoảng 1,715 ha, trong đó diện tích tập trung chủ yếu ở Đà Lạt với diện tích 913.9 ha chiếm $53 \%$ diện tích canh tác toàn tỉnh (Sở Nông nghiệp và Phát triển Nông thôn tỉnh Lâm Đồng, 2016).

Khoai tây là cây trồng rất mẫn cảm với các loại dịch bệnh, côn trùng, và tuyến trùng gây hại, trong đó tuyến trùng là nhóm dịch hại quan trọng (Mugniéry \& Phillips, 2007). Tuyến trùng là nhóm ký sinh quan trọng, làm tổn thương trực tiếp với cây trồng và có tác dụng gián tiếp đến việc lây nhiễm của các loại nấm, vi khuẩn, và véc tơ truyền virus. Ngoài ra, các nhóm tuyến trùng tự do trong đất có vai trò quan trọng có liên quan đến chu trình dinh dưỡng và bền vững sinh thái trong đất (Palomares, Oliveria, \& Blok, 2014). Hàng năm, tuyến trùng ký sinh thực vật có thể giảm thiệt hại về năng suất lên đến 100 tỷ đô la ở nước Mỹ và khoảng 125 tỷ đô la trên toàn thế giới (Chitwood, 2003).

Vì khoai tây là cây trồng có vai trò quan trọng trong nông nghiệp, nên đã có nhiều nghiên cứu và công bố về các nhóm tuyến trùng ký sinh quan trọng trên đối tượng này (Alphey, Woodford, \& Gordon, 1986; Cadima \& ctg., 2014; Kimpinski, 1987; Minor \& Bond, 2016). Tuy nhiên, việc điều tra xác định thành phần gây hại và các biện pháp phòng trừ chủ yếu tập trung trên các nhóm tuyến trùng ký sinh quan trọng như tuyến trùng bào nang (Gray, Curtis, \& Jones, 2001), tuyến trùng nốt sưng (Wesemael, Taning, Viaene, \& Moens, 2014), tuyến trùng thối rễ (Kimpinski, 1987), tuyến trùng gây bối rễ, còi cọc và ít khả năng tạo củ (Wale, Platt, \& Cattlin, 2008). Các nhóm tuyến trùng ký sinh còn lại cũng được xếp vào nhóm tuyến trùng ký sinh gây hại quan trọng như Ditylenchcus sp., Scutellonema sp., và Nacobbus (Bridge \& Starr, 2007; Luc, Shikora, \& Bridge, 2005; \& Palomares \& ctg., 2014).

Ở Việt Nam, tình hình nghiên cứu về tuyến trùng chưa nhiều, chủ yếu điều tra xác định thành phần loài tuyến trùng trên một số cây trồng như cà rốt (Nguyễn, Lê, Nguyễn, \& Trịnh, 2016), lạc (Nguyễn, Lê, \& Nguyễn, 1994), gừng (Trần, 2012), cây dược liệu (Nguyễn, Nguyễn, Lê, \& Trịnh, 2015), và cây cà phê (Trần \& Nguyễn, 2011). Hiện nay, chưa có tài liệu công bố độc lập về thành phần tuyến trùng ký sinh trên khoai tây ở Lâm Đồng. Chỉ có một số nghiên cứu về thành phần loài tuyến trùng ký sinh trên một số cây rau ở miền nam Việt Nam và Đà Lạt, trong đó có điều tra về thành phần tuyến trùng ký sinh trên khoai tây (Bin, 1990; Khuong, 1983).

Khoai tây là một trong những cây trồng quan trọng ở Lâm Đồng và tuyến trùng cũng là một trong những đối tượng dịch hại phổ biến và gây thiệt hại về năng suất và chất lượng cho khoai tây. Vì thế nghiên cứu thành phần tuyến trùng ký sinh thực vật gây hại trên khoai tây có vai trò quan trọng trong việc xác định biện pháp phòng trừ. 


\section{VẬT LIỆU VÀ PHƯƠNG PHÁP NGHIÊN CÚU}

\subsection{Vật liệu nghiên cứu}

Vật liệu nghiên cứu là đất trồng khoai tây và rễ khoai tây được thu thập từ 30 vườn trồng khoai tây ở các phường 7,8 , xã Xuân Thọ, Xuân Trường, và Trạm Hành thuộc thành phố Đà Lạt.

\subsection{Phương pháp nghiên cứu}

Mẫu đất và rễ được tiến hành lấy từ các điểm riêng biệt, theo phương pháp đánh dấu bản đồ, theo qui tắc hình zích zắc (Bezooijen, 2006). Mẫu đất được lấy từ vùng rễ ở độ sâu khoảng 5 đến $10 \mathrm{~cm}$, đảm bảo đủ khối lượng mỗi mẫu đất khoảng $500 \mathrm{~g}$ và mẫu rễ khoảng 5g (Ravichandra, 2010).

Mức độ gây hại của tuyến trùng nốt sưng được xác định theo phương pháp của Bridge và Page (1980); Zeck (1971). Mức độ nhiễm tuyến trùng nốt sưng được tác giả xếp hạng từ 0 đến 10. Cách mô tả mức độ gây hại như sau: Mức 0 là không có nốt sưng; Mức 1 là có một vài nốt sưng nhỏ rất khó tìm thấy; Mức 2 là những nốt nhỏ có thể nhìn thấy dễ dàng, rễ chính không có nốt sưng; Mức 3 có một vài nốt sưng lớn, rễ chính không có nốt sưng; Mức 4 có nốt sưng lớn nhưng rễ chính không có nốt sưng; Mức 5 có khoảng $50 \%$ rễ bị xâm nhiễm, một phần của rễ chính có nốt sưng, giảm rễ tơ; Mức 6 là nhìn thấy các nốt sưng trên rễ chính; Mức 7 là phần lớn các rễ bị u sưng; Mức 8 là tất cả các rễ chính đều bị u sưng; Mức 9 là u sưng nghiêm trọng rễ chính; và Mức 10 là tất cả các rễ đều bị sưng nghiêm trọng, cây thường chết.

Tách chiết và xác định mật số tuyến trùng ký sinh trong đất bằng phương pháp Baermann cải biên (Hooper, Hallmann, \& Subbotin, 2005; Staniland, 1954): Đất lấy về phòng thí nghiệm, được rây qua rây có kích thước $2 \mathrm{~mm}$ rồi trộn đều trên giấy báo và đong đủ $50 \mathrm{~cm}^{3}$ trên cốc đong có thể tích $50 \mathrm{~cm}^{3}$. Sau đó đặt đất lên rây có lót giấy lọc sữa ở trên và được đặt trên các đĩa có đường kính $18 \mathrm{~cm}$, dàn đều đất trên giấy lọc. Đổ nước từ từ cho đất vừa ngấm nước, tránh đổ trực tiếp lên đất. Để yên trong vòng 48 giờ, tiến hành tách chiết và đếm tuyến trùng trong đất trên kính lúp có độ phóng đại 40 lần.

Tách chiết và xác định mật số tuyến trùng trong rễ bằng phương pháp Baemann cải biên (Hooper, Hallmann, \& Subbotin, 2005; Staniland, 1954). Rễ sau khi lấy về được rửa qua nước, để ráo, cân đủ $5 \mathrm{~g}$ rễ trên cân kỹ thuật có độ chính xác $0.001 \mathrm{~g}$. Sau đó cắt rễ ra thành từng đoạn nhỏ khoảng 1 đến $2 \mathrm{~cm}$, cho lên rây có lót giấy lọc sữa và đặt trên đĩa. Cho nước thấm đều rễ. Thu tuyến trùng sau 48 giờ ủ.

Làm tiêu bản và bảo quản mẫu: Sử dụng vật dụng chuyên dụng để bắt tuyến trùng và làm tiêu bản cố định để bảo quản mẫu trong hốn hợp Formalin + Glycerine (Bezooijen, 2006) Tiêu bản được quan sát dưới kính hiển vi có độ phóng đại lần lượt là $4 X, 10 X$, $40 X$, và $100 X$. Phân loại tuyến trùng bằng phương pháp mô tả hình thái tuyến trùng tuổi 2 (J2) hoặc tuyến trùng trưởng thành. 


\subsection{Xử lý số liệu}

Số liệu được tổng hợp và thống kê bằng phần mềm Microsoft Excel 2010 và xử lý thống kê ANOVA bằng phần mềm MSTATC.

\section{KẾT QUẢ VÀ THẢO LUẬN}

\subsection{Thành phần tuyến trùng ký sinh thực vật trên khoai tây}

Kết quả điều tra thành phần tuyến trùng của 30 vườn trồng trên cây khoai tây trồng tại thành phố Đà Lạt được thể hiện qua Bảng 1.

\section{Bảng 1. Thành phần tuyến trùng ký sinh thụ̣c vật trên khoai tây}

\begin{tabular}{|c|c|c|}
\hline STT & Phân loại các giống tuyến trùng ký sinh & Tần suất $(\%)$ \\
\hline \multicolumn{3}{|c|}{ Bộ Tylenchida Thorne, 1949} \\
\hline \multicolumn{3}{|c|}{ Họ Hoplolaimidae Filipjev, 1934} \\
\hline 1 & Globodera Skarbilovich, 1959 & 20.00 \\
\hline 2 & Helicotylenchus Steiner, 1945 & 93.33 \\
\hline \multicolumn{3}{|c|}{ Họ Meloidogynidae Skarbilovich, 1959} \\
\hline 3 & Meloidogyne Göldi, 1887 & 83.33 \\
\hline \multicolumn{3}{|c|}{ Họ Pratylenchidae Thorne, 1949} \\
\hline 4 & Pratylenchus Filipjev, 1936 & 50.00 \\
\hline \multicolumn{3}{|c|}{ Họ Criconematidae Taylor, 1936} \\
\hline 5 & Criconemella ${ }^{l}$ Hofmänner \& Menzel, 1914 & 33.33 \\
\hline \multicolumn{3}{|c|}{ Họ Anguinidae Nicoll, 1935 (1926) } \\
\hline 6 & Ditylenchus (Filipjev, 1936) & 30.00 \\
\hline
\end{tabular}

Chi chú: ${ }^{1}$ Criconemoides.

Kết quả điều tra xác định được sáu giống tuyến trùng ký sinh thực vật thuộc năm họ và một bộ gây hại trên khoai tây. Trong đó với tần suất xuất hiện nhiều nhất là giống Helicotylenchus với tần suất xuất hiện $93.33 \%$, tiếp theo là Meloidogyne $(83.33 \%)$, Pratylenchus (50\%). Giống Globodera với tần suất xuất hiện thấp nhất, chỉ chiếm $20 \%$ tổng số mẫu điều tra.

Xét về mức độ gây hại thì nhóm tuyến trùng nội ký sinh cố định gây sần rễ và tuyến trùng bào nang có mức độ gây hại và gây tổn thất về năng suất cũng như chất lượng của khoai tây nhiều nhất. Tuyến trùng bào nang được xếp vào nhóm có dịch hại chính trên khoai tây (Ravichandra, 2014). Về giống tuyến trùng Globodera đã tìm thấy ba loài gây hại trên khoai tây là G. rostochiensis, G. pallida, và G. ellingtonae (Palomares \& ctg., 2014; Ravichandra, 2014; \& Perry, Moens, \& Jones, 2018) Tuyến trùng bào nang xâm nhiễm vào rễ, gây ra các tổn thương rễ và tạo tiền đề các các loại nấm gây thối rễ̂, gây héo phát triển (Palomares, \& ctg., 2014). Còn giống tuyến trùng nốt sưng Meloidogyne là nhóm tuyến trùng quan trọng nhất, có phổ ký chủ rộng, gây thiệt hại về kinh tế cho các 
loại cây rồng, đặc biệt là cây trồng ở vùng có khí hậu ấm (Palomares \& ctg., 2014). Đã có gần 100 loài công bố về giống tuyến trùng nốt sưng gây hại trên các cây trồng khác nhau trên thế giới (Karssen, Wesemael, \& Moens, 2013), tuy nhiên chỉ có sáu loài tuyến trùng nốt sưng gây hại trên khoai tây bao gồm $M$. incognita, $M$. Javanica, $M$. hapla, M.chitwoodi và M. fallax (Palomares \& ctg., 2014). Trong đó loài $M$. incognita và $M$. javanica gây hại trên khoai tây ở những vùng nhiệt đới và cận nhiệt đới. Ở Việt Nam, đã tìm thấy loài $M$. arenaria trên khoai tây (Nguyễn \& Nguyễn, 2000).

Tuyến trùng nội ký sinh di chuyển Pratylenchus là nhóm tuyến trùng ký sinh quan trọng trên các loại cây trồng khác nhau và cũng là loại gây hại phổ biến trên khoai tây. Đã ghi nhận có chín loài tuyến trùng thối rễ gây hại trên khoai tây bao gồm $P$. brachyurus, $P$. coffea, $P$. crenatus, $P$. neglectus, $P$. thornei, $P$. scribneri, $P$. penetrans, $P$. flakkensis, và $P$. vulnus. Ở những vùng nhiệt đới $P$. brachyurus và $P$. coffeae là hai loài gây hại phổ biến trên khoai tây (Palomares \& ctg., 2014). Ditylenchus là nhóm tuyến trùng hại rễ, hầu hết vòng đời của chúng là xâm nhập vào bên trong rễ và củ (Bridge \& Starr, 2007). Khi xâm nhập vào rễ nhóm tuyến trùng này thường gây thối rễ (Ravichandra, 2014). Ở Việt Nam đã xác nhận được loài $D$. ausaffi trong đất và rễ khoai tây (Nguyễn \& Nguyễn, 2000)

Hai nhóm tuyến trùng ngoại ký sinh di chuyển là Helicotylenchus và Criconemella phổ biến rộng khắp trên thế giới và có phổ ký chủ rộng (Ravichandra, 2014). Tuy hai giống tuyến trùng này có tần suất bắt gặp cao nhưng mức độ gây thiệt hại về mặt năng suất và kinh tế không nhiều. Ở Việt Nam, phát hiện 30 loài thuộc giống Helicotylenchus ký sinh trên các loại cây trồng khác nhau, trong đó có năm loài bao gồm $H$. cornurus, $H$. crassatus, $H$. digonicus, $H$. exallus, và $H$. vulgaris xung quanh vùng rễ khoai tây ở Việt Nam (Nguyễn \& Nguyễn, 2000). Còn giống Criconemella chưa phát hiện loài nào xung quanh vùng rễ khoai tây.

\subsection{Mật số tuyến trùng trong đất}

Kết quả điều tra mật số tuyến trùng trên đất được thể hiện qua Hình 1.

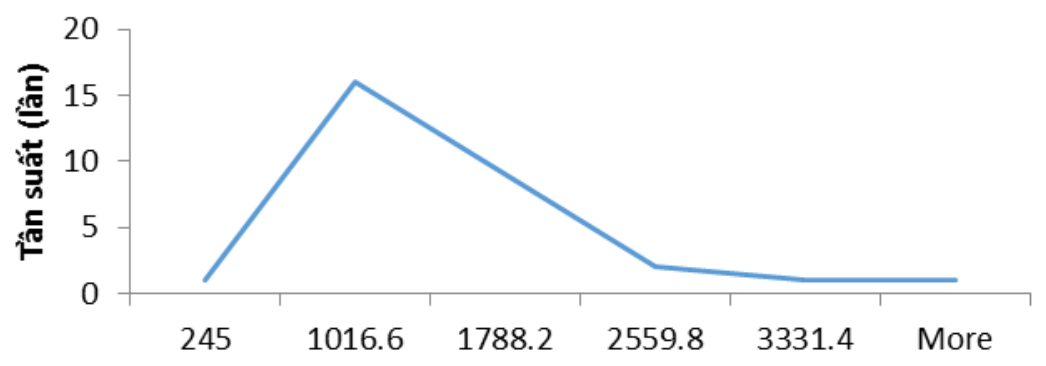

\section{Hình 1. Số lượng tuyến trùng trong $50 \mathrm{~cm}^{3}$ đất}

Mật số tuyến trùng ký sinh thực vật trong đất dao động từ 245 cá thể đến trên 3,331 cá thể trong $50 \mathrm{~cm}^{3}$ đất. Trong đó, mật số tuyến trùng phổ biến vào khoảng từ 1,000 đến 2,000 cá thể trong $50 \mathrm{~cm}^{3}$ đất. Với số lượng tuyến trùng ở mức này có thể gây hại đến nặng đến $50 \%$ hệ rễ của cây. Theo Perry, Moens, và Starr (2009) thì với ngưỡng tuyến trùng nốt sưng chỉ khoảng hai cá thể trên 1 gram đất thì đã gây hại đối với cây trồng. 


\subsection{Mật số tuyến trùng trong rễ}

Kết quả điều tra mật số tuyến trùng trong $5 \mathrm{~g}$ rễ được thể hiện qua Hình 2.

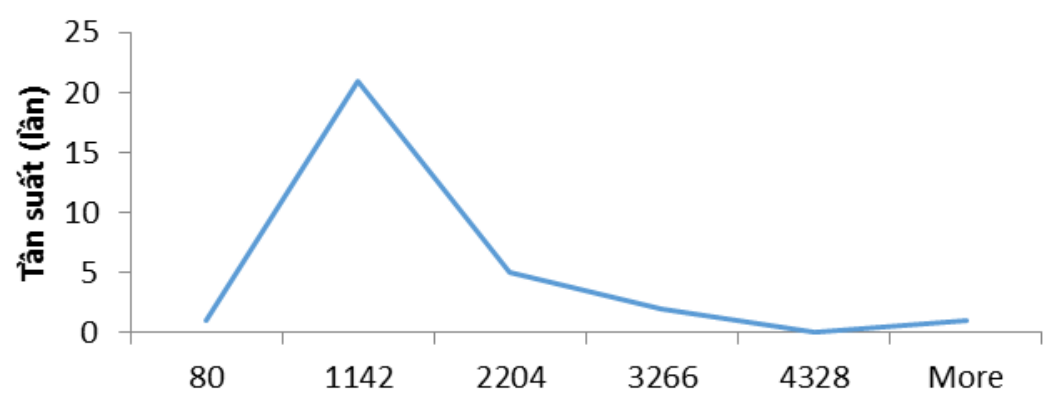

Hình 2. Mật số tuyến trùng trong $5 \mathrm{~g}$ rễ

Mật số tuyến trùng trong $5 \mathrm{~g}$ rễ dao động từ 80 đến 4,328 cá thể. Trong đó mật số tuyến trùng phổ biến ở mức từ 200 đến 2,204 cá thể có tần suất xuất hiện cao nhất. Với mật số này thì rễ khoai tây bị tuyến trùng gây hại khá lớn và thể hiện những triệu chứng điển hình trên rễ của khoai tây như có nhiều vết thương, nốt sưng xuất hiện trên rễ chính và rễ phụ.

\subsection{Mức gây hại của tuyến trùng trên rễ}

Chỉ số hại của tuyến trùng trên rễ dao động từ 0 đến 7,016, với mức gây hại phổ biến từ 1,754 đến mức 5,262 (Hình 3 ).

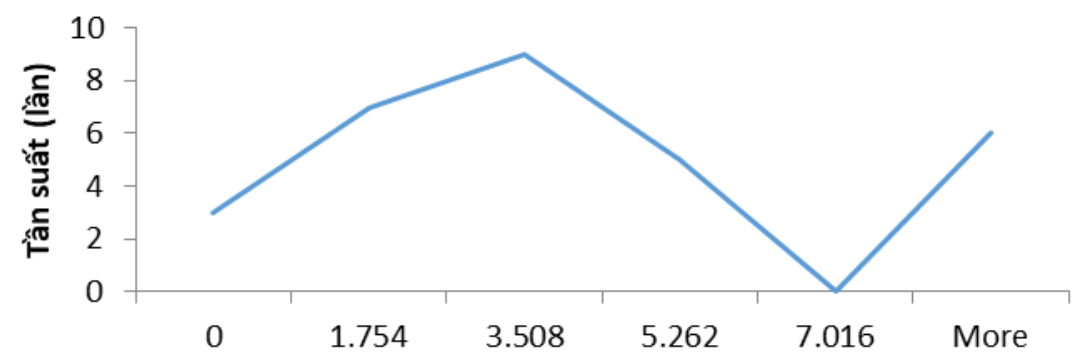

Hình 3. Mức gây hại của tuyến trùng

Theo Zeck (1971); Bridge và Page (1980) thì chỉ số hại này đã có sự xuất hiện nốt sưng ở hầu hết các rễ phụ và rễ cấp 2 và một phần đã gây tổn thương lên rễ chính của cây. Ngưỡng gây hại này có thể làm tổn thương đến trên $50 \%$ hệ rễ của khoai tây.

\section{KẾT LUẬn}

Từ kết quả trên, rút ra các kết luận sau:

- Đã xác định được sáu giống tuyến trùng thuộc năm họ và một bộ tuyến trùng ký sinh gây hại trên thực vật bao gồm Helicotylenchus, Meloidogyne, Pratylenchus, Globodera, Criconemella, và Ditylenchus; 
- Mật số tuyến trùng trong đất phổ biến từ 500 đến 2,000 cá thể trong $50 \mathrm{~cm}^{3}$ đất và 200 đến 2,204 cá thể trong 5 gam rễ và chỉ số hại phổ biến trên rễ khoai tây trồng tại Đà Lạt là từ mức 1,754 đến mức 5,262. Đây là ngưỡng gây hại có thể gây nốt sưng và tổn thương đến hơn $50 \%$ hệ rễ của khoai tây.

Với kết quả nghiên cứu trên, người nông dân cần có biện pháp canh tác cây trồng phù hợp để giảm thiểu tác hại của tuyến trùng gây hại trên khoai tây cụ thể không nên trồng khoai tây trong nhiều vụ liên tiếp, không luân canh cây cùng họ cà và không luân canh khoai tây với cà rốt.

\section{TÀI LIỆU THAM KHẢO}

Alphey, T. J. W., Woodford, J. A. T., \& Gordon, S. C. (1986). Field and laboratory studies on the control of nematode and aphid virus vectors in potatoes by pesticides applied as side-bands. Crop Protection, 5(2), 114-121.

Bezooijen, J. V. (2006). Methods and techniques for nematology. Retrieved from http:// www.nematologia.com.br/files/tematicos/5.pdf.

Bin, F. T. (1990). Gall nematodes of vegetables and potatoes in Dalat (Tei Nguen Plateau, Vietnam) and description of Meloidogyne cynariensis, a parasite of artichokes. Zoologicheskii Zhurnal, 69(4), 128-131.

Bridge, J., \& Page, L. J. (1980). Estimation of root-knot nematode infestation levels on roots using a rating chart. Tropical Pest Management, 26(3), 296-298.

Bridge, J., \& Starr, J. L. (2007). Plant nematodes of agricultural importance. Barcelona, Spain: Manson Publishing.

Cadima, X., Zonneveld, M. V., Scheldeman, X., Castañeda, N., Patiño, F., Beltran, M., \& Damme, P. V. (2014). Endemic wild potato (Solanum spp.) biodiversity status in Bolivia: Reasons for conservation concerns. Journal for Nature Conservation, 22(2), 113-131.

Chitwood, D. J. (2003). Research on plant-parasitic nematode biology conducted by the United States department of Agriculture - Agricultural Research Service. Pest Management Science, 59, 748-753.

FAOSTAT. (2017). Crop. Retrieved from http://www.fao.org/faostat/en/?\#data/QC.

Gray, L. J., Curtis, R. H., \& Jones, J. T. (2001). Characterisation of a collagen gene subfamily from the potato cyst nematode Globodera pallida. Gene, 263(1-2), 6775 .

Hooper, D. J., Hallmann, J., \& Subbotin, S. A. (2005). Methods for extraction, processing and detection of plant and soil nematodes. In M. Luc, R. A. Sikora, \& J. Bridge (Eds.), Plant parasitic nematodes in subtropical and tropical agriculture. Wallingford, UK: CAB International.

Karssen, G., Wesemael, W., \& Moens, M. (2013). Root-knot nematodes. In M. M. Perry (Eds.), Plant nematology. London, UK: CABI Publishing. 
Khuong, N. B. (1983). Plant parasitic nematodes of south Vietnam. Journal of Nematology, 15(2), 319-323.

Kimpinski, J. (1987). Nematodes associated with potato in priince edward island and new brunswick. Annual of Applied Nematology, 1, 17-19.

Luc, M., Shikora, R. A., \& Bridge, J. (2005). Plant parasitic nematodes in subtropical and tropical agriculture ( $2^{\text {nd }}$ ed.). London, UK: CABI Publishing.

Minor, T., \& Bond, J. K. (2016). Potatoes survey. Retrieved from https://www. ers.usda.gov/topics/crops/vegetables-pulses/potatoes.aspx.

Mugniéry, D., \& Phillips, M. S. (2007). The nematode parasites of potato. In D. Vreugdenhil, J. Bradshaw, C. Gebhardt, F. Govers, D. K. L. Mackerron, M. A. Taylor, \& H. A. Ross (Eds.), Potato biology and biotechnology (pp. 569-594). Amsterdam, Nederland: Elsevier Science.

Nguyễn, H. T., Nguyễn, T. D., Lê, T. M. L., \& Trịnh, Q. P. (2015). Buoóc đầu khảo sát tuyến trùng ký sinh thực vật trên một số cây dược liệu tại Đông Triều, Quảng Ninh. Bài báo được trình bày tại Hội nghị Khoa học Toàn quốc về Sinh thái và Tài nguyên Sinh vật, Việt Nam.

Nguyễn, N. C., \& Nguyễn, V. T. (2000). Động vật chí Việt Nam (Tập 4). Hà Nội, Việt Nam: NXB Khoa học và Kỹ thuật.

Nguyễn, T. D., Lê, T. M. L., Nguyễn, H. T., \& Trịnh, Q. P. (2016). Bước đầu điều tra thành phần loài tuyến trùng ký sinh gây hại trên cà rốt ở Hải Dương. Tạp chí Sinh hoc, 38(1), 6-13.

Nguyễn, V. V., Lê, V. T., \& Nguyễn, X. H. (1994). Thành phần tuyến trùng hại lạc ở miền Bắc Việt Nam. Tạp chí Bảo vệ Thục vật, (3), 1-4.

Palomares, R. J. E., Oliveria, C. M. G., \& Blok, V. C. (2014). Plant parasitic nematodes of potato. In R. Navarre \& M. J. Pavek (Eds.), The potato botany, production, and uses (pp. 149-161). London, UK: CABI Publishing.

Perry, R. N., Moens, M., \& Jones, J. T. (2018). Cyst nematodes. London, UK: CABI Publishing.

Perry, R. N., Moens, M., \& Starr, J. L. (2009). Root knot nematodes. London, UK: CABI Publishing.

Ravichandra, N. G. (2010). Methods and techniques in plant nematology. New Delhi, India: PHI learning Private Limited.

Ravichandra, N. G. (2014). Horticultural nematology. Berlin, Germany: Springer Publishing.

Rodríguez, K. R., \& Pope, M. H. (1981). A simple incubation method for exaction of nematodes from soil. Nematropica, 11(2), 175-185.

Sở Nông nghiệp và Phát triển Nông thôn tỉnh Lâm Đồng. (2016). Biểu tổng hợp trồng trọt tỉnh Lâm Đồng. Lâm Đồng, Việt Nam: Sở Nông nghiệp và Phát triển Nông thôn tỉnh Lâm Đồng 
Staniland, L. N. (1954). A modification of the Baermann funnel technique for the collection of nematodes from plant material. Journal of Helminthology, 18(1/2), 115-117.

Trần, T. T. H., \& Nguyễn, T. T. (2011). Nghiên cứu thành phần và mật số tuyến trùng gây hại trên cây hồ tiêu tại Cam Lộ, Quảng Trị. Tạp chí Khoa học Đại học Huế, 67(4), 5-12.

Trần, V. P. (2012). Thành phần tuyến trùng ký sinh trên gừng tại An Giang. Tạp chí Khoa học Truò̀ng Đại học Cần Tho, (1), 262-267.

Wale, S., Platt, H. W. B., \& Cattlin, N. (2008). Diseases, pests, and disorders of potatoes. London, UK: Manson Publishing.

Wesemael, W. M. L., Taning, L. M., Viaene, N., \& Moens, M. (2014). Life cycle and damage of the root-knot nematode Meloidogyne minor on potato, Solanum tuberosum. Nematology, 16, 185-192.

Zeck, W. M. (1971). A rating schem for field evaluation of root-knot nematode infestation. Pflanzenschurtz Nachrichten, 24, 142-144. 